scattered over the west and central parts of Kenya. There were no specimens from northern, north-eastern, or coastal areas or tribes.

\section{Discussion}

It is not our intention to discuss the causation of tumoral calcinosis. Our information is limited only to the few remarks on the biopsy form sent in with the specimen, and follow-up is impossible under present circumstances. From the data we have, and it should be realized that we deal almost exclusively with Africans, it appears that various ethnic groups-Hamitic, Nilo-Hamitic, and Bantu-have the disease. There is a slight preponderance of females, which is the opposite of Palmer's (1966) findings, and no obvious age limitation from the second decade onwards. As in the previous series, the sites of tumours are near joints. Unlike the cases reported by Palmer (1966) and Thomson (1966) we had none near the shoulder or scapula, which would cast doubt on the thesis that pressure on certain areas during sleep or resting on the ground or on hard beds predisposed to its location there. However, the great preponderance of tumours in "pressure areas" around the hips, with ulceration and even perforation in some cases, cannot be dismissed as pure chance.
Another point of difference in our series is that we have seen occasional bone formation, so that the condition is not quite "the exact reverse of myositis ossificans" as suggested by Thomson (1966). However, we have no theory to offer regarding its causation.

It is worth mentioning for its negative value that we obtained a sterile specimen from the one case that came to our hospital. No organisms could be grown. At the moment surgical excision is the only effective treatment.

We wish to thank Mr. N. Ahmed, formerly provincial surgeon, Nyanza, and now in Australia, and Mr. J. R. M. Miller, surgical consultant, Kenyatta National Hospital, Nairobi, for their assistance with some of these cases. At Mr. Miller's suggestion Dr. Palmer was consulted and provided the missing clues to the proper diagnosis. Mr. J. A. M. White, senior lecturer, Department of Surgery, University College of Rhodesia, confirmed Professor Palmer's findings.

\section{REFERENCES}

Palmer, P. E. S. (1966). Brit. f. Radiol., 39, 5.18.

Thomson, J. G. (1966). Brit. f. Radiol., 39, 526.

\title{
Effects of Phenoxybenzamine in Shock due to Myocardial Infarction
}

\author{
J. F. RIORDAN,* M.B., M.R.C.P.; G. WALTERS, † M.D., M.R.C.P., M.C.PATH.
}

Brit. med. F., 1969, 1, 155-158

\begin{abstract}
Cummary : Treatment of cardiogenic shock with vaso$\checkmark$ dilator drugs has been advocated on the basis of experimental work showing that a fall in peripheral resistance allows the cardiac output to increase without any increase in cardiac work.

Seven patients suffering from shock secondary to myocardial infarction were treated with phenoxybenzamine. In two cases there was dramatic improvement in the signs and symptoms of shock, but in six of the seven cases there were severe adverse effects on respiration, including the development of wheezing and rales and rhonchi.
\end{abstract}

\section{Introduction}

When myocardial infarction is accompanied by hypotension and weak or impalpable peripheral pulses, together with pallor, cyanosis, clouding of consciousness, and oliguria, the mortality is greater than $80 \%$ (Epstein and Relman, 1949 ; Cronin et al., 1965). Many therapeutic regimens have been advocated for this state but none has become generally accepted.

Vasopressors are usually considered to be of little value and even harmful (Lancet, 1966), though these views are not universally held (Kuhn, 1967), and it has been suggested that vasodilator drugs be tried instead in view of their beneficial effects in experimental cardiogenic shock, in which it was thought that the resulting fall in peripheral resistance allowed increased cardiac output without any increase in cardiac work (Dietzman et al., 1967).

* Research Registrar, the Royal Hospital, Wolverhampton.

t Consultant Pathologist, the Royal Hospital, Wolverhampton.
Reports of the use of phenoxybenzamine in patients with shock due to myocardial infarction are sparse and give few details of its effects (Wilson et al., 1964 ; Pentecost and Mayne, 1968). Our own experience with this drug in such patients is limited. Though we have obtained beneficial results in two patients, our main purpose in this article is to draw attention to hitherto undescribed adverse effects which may prove fatal in some cases.

\section{Patients Studied and Methods}

Some details of the seven patients we have treated are given in Table I. The clinical diagnosis of myocardial infarction was substantiated either by diagnostic electrocardingraphic (E.C.G.) changes or by suggestive E.C.G. changes accompanied by a rise in serum aspartate aminotransferase activity. Infarction was confirmed at necropsy in four of the six patients who died ; in the other two, who died within 24 hours of the onset, only coronary occlusion was demonstrable.

In all cases a systolic blood pressure of $80 \mathrm{~mm}$. Hg or less was associated with weak or impalpable peripheral pulses, pallor, cold moist extremities with constricted veins, mental confusion, and restlessness. Urine output was $25 \mathrm{ml}$./hour or less in all, and five were anuric. These signs were present for at least four hours before treatment with phenoxybenzamine was begun and had not improved with standard treatment, including oxygen by face-mask, diuretics, adequate analgesia, and control of arrhythmias. Vasopressors were not used. The prognosis appeared to be very poor and the Peel prognostic index (Peel et al., 1962) confirmed this. 
Arterial blood pressure was measured by sphygmomanometry. Central venous pressure was measured in all cases relative to the sternal angle by means of a catheter in the superior vena cava or innominate vein and a saline manometer. The position of the catheter, which was kept patent with a very slow heparinized drip, was established radiologically except in Case 3, where at necropsy it was found to be in the internal jugular

TABLE I.-Findings in Seven Men with Myocardial Infarction, Before Treatment with Phenoxybenzamine

\begin{tabular}{|c|c|c|c|c|c|c|c|c|c|c|}
\hline \multirow[b]{2}{*}{ 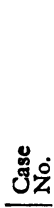 } & \multirow[b]{2}{*}{$\stackrel{8}{4}$} & \multirow[b]{2}{*}{ 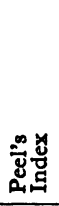 } & \multirow[b]{2}{*}{ 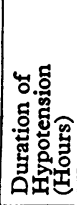 } & \multirow[b]{2}{*}{ 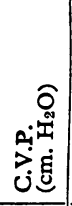 } & \multirow[b]{2}{*}{ 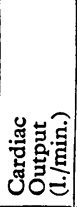 } & \multirow[b]{2}{*}{ 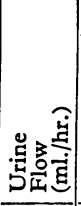 } & \multicolumn{4}{|c|}{ Arterial Blood } \\
\hline & & & & & & & 崫 & 莡 & 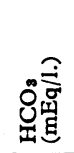 & 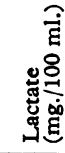 \\
\hline $\begin{array}{l}1 \\
2 \\
3 \\
4 \\
5 \\
6 \\
7\end{array}$ & $\begin{array}{l}58 \\
65 \\
39 \\
55 \\
57 \\
56 \\
61\end{array}$ & $\begin{array}{l}25 \\
24 \\
21 \\
21 \\
18 \\
22 \\
26\end{array}$ & $\begin{array}{r}4 \\
24 \\
12 \\
4 \\
8 \\
9 \\
14\end{array}$ & $\begin{array}{r}+10 \\
+7 \\
+12 * \\
+9 \\
+6 \\
+17 \\
+7\end{array}$ & $\begin{array}{l}Z \\
\bar{Z} \\
3 \cdot 1+ \\
2 \cdot 4 \\
2 \cdot 4\end{array}$ & $\begin{array}{r}0 \\
25 \\
0 \\
0 \\
0 \\
20 \\
0\end{array}$ & $\begin{array}{l}7 \cdot 35 \\
7 \cdot 31 \\
7 \cdot 44 \\
7 \cdot 48 \ddagger \\
7 \cdot 25 \\
7 \cdot 47\end{array}$ & $\begin{array}{l}34 \\
48 \\
24 \\
21 \cdot 5 \ddagger \\
35 \cdot 5 \\
38.5\end{array}$ & $\begin{array}{l}20 \cdot 5 \\
21 \cdot 6 \\
20 \cdot \overline{5} \\
20 \cdot 0 \ddagger \\
16 \cdot 3 \\
27 \cdot 0\end{array}$ & $\begin{array}{l}33 \cdot \overline{6} \\
\overline{=} \\
28 \cdot \overline{5} \\
41 \cdot 0 \\
34.7\end{array}$ \\
\hline
\end{tabular}

* Catheter in internal jugular vein.

† Measurement taken eight hours before treatment, when central venous pressure was -4 (see case report).

$\ddagger$ Measurements taken 30 minutes after beginning of treatment.

vein. Cardiac output was measured by a dye dilution method using Coomassie blue (sodium anoxynaphthonate) and a photoelectric earpiece (Cambridge Instrument Co.) ; the instrument was modified according to Gabe and Shillingford (1961) and the linearity of response checked by replicate measurements on normal subjects. The area under the curve was calculated by the method of Dow (1955) to eliminate false low values, which may occur in low output states owing to distortion of the down slope of the curve by recirculation (Oriol and McGregor, 1967). Arterial blood $\mathrm{pH}, \mathrm{PcO}_{2}$, and standard bicarbonate were measured by the method of Astrup et al. (1960), arterial blood lactate with lactate dehydrogenase (Boehringer), and urine flow by continuous bladder drainage.

Phenoxybenzamine $1 \mathrm{mg}$. $/ \mathrm{kg}$. estimated body weight was given intravenously in $200 \mathrm{ml}$. of $5 \%$ dextrose in half to two hours (Nickerson, 1962 ; Wilson et al., 1964); a slower rate was adopted for three of the last four cases for reasons which are stated. The effect was judged by continuous clinical observation of the patient's general state, blood pressure, pulse rate and volume, skin temperature and colour, urine flow, central venous pressure, and, when possible, by measurement of cardiac output. At least one of us stayed at the bedside continuously while the drug was being given; alterations of pulse volume and skin temperature were assessed independently by both of us and improvement was discounted unless there was agreement.

\section{Observations}

The patients were grouped according to the apparent overall effect of phenoxybenzamine, and are not in chronological order.

\section{Probable Harmful Effect (Cases 1-3)}

The sequence of events was the same in these three patients, who died very soon after the infusion, which lasted 45,30 , and 85 minutes respectively. The central venous pressure fell by $5-8 \mathrm{~cm}$. within 80 minutes of starting treatment, but there was no other sign of circulatory improvement. In all three, however, the fall in central venous pressure was accompanied by the appearance of a striking picture of respiratory difficulty with loud wheezing audible from a distance of several feet; only in Case 2 were there rales and rhonchi before phenoxybenzamine was begun. The picture at first resembled bronchial asthma with a prolonged expiratory phase, but rapidly worsened to resemble laryngeal spasm, followed by respiratory arrest 40 ,
15 , and 75 minutes respectively after completing the infusion. In all cases direct laryngoscopy revealed patent vocal chords, and, in Case 2, pulmonary oedema fluid in the larynx. Positivepressure ventilation with $100 \%$ oxygen through an endotracheal tube was of no avail and cardiac arrest occurred. Gross pulmonary oedema was found in all three at necropsy.

\section{Equivocal Effect (Cases 4 and 5)}

These two patients also died, but they survived much longer after phenoxybenzamine was begun and appeared to show some circulatory improvement, as judged by an increase in pulse volume and skin temperature, and in Case 5 secretion of urine. In both cases the drug was temporarily discontinued because of its apparent effects.

Case 4.-The patient had developed cardiac arrest due to ventricular fibrillation four days after admission and was successfully resuscitated ; five days later he became shocked. Four hours after the onset of shock an infusion of phenoxybenzamine was begun, and in view of the effects in the earlier cases was given more slowly. The central venous pressure fell slowly and at the same time the respiratory rate increased, the few basal rales present initially became widespread, and generalized rhonchi appeared (Fig. 1). He did not show the severe syndrome of the first group, but phenoxybenzamine was nevertheless discontinued. These signs disappeared during the next few hours and the pulse volume improved slightly, but he was so restless and confused that cardiac output measurements with the earpiece detector were technically unsatisfactory. The remainder of the dose was given later without any obvious effect apart from a temporary increase in respiratory rate and a slight increase in rales.

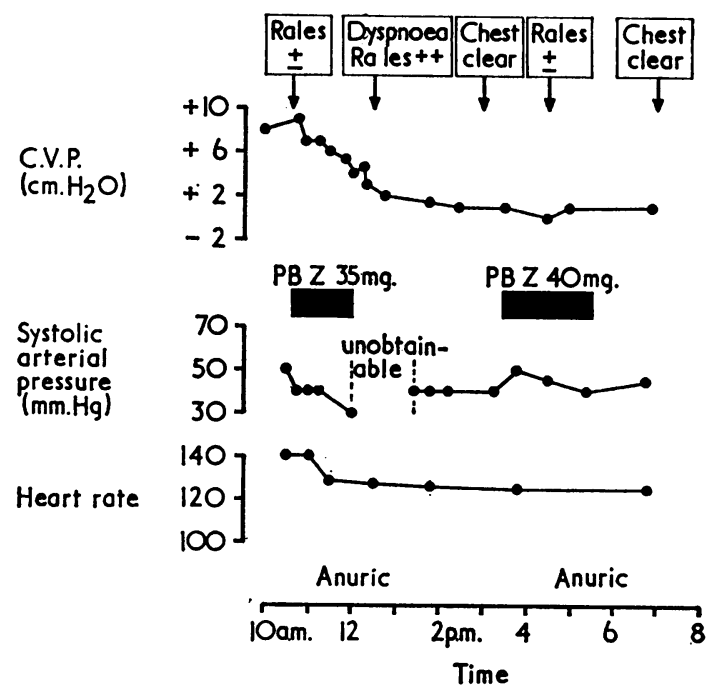

FIG. 1.-Effect of phenoxybenzamine (PBZ) in Case 4. Treatment was temporarily discontinued because of increase in respiratory rate and rales. Death occurred one hour after the period illustrated.

Case 5.-This patient, who had a past history of hypertension and angina, became shocked three days after admission with a myocardial infarct. Shortly after the onset of shock the central venous pressure was $-4 \mathrm{~cm}$. of water and cardiac output was $3.1 \mathrm{l} . / \mathrm{min}$. (Fig. 2). During the next six hours he deteriorated, and when seen again was unconscious. The central venous pressure had risen to $+6 \mathrm{~cm}$., and there was severe pulmonary oedema. Phenoxybenzamine was begun therefore at a rapid rate, without obtaining a baseline cardiac output, and it produced a rapid fall in central venous pressure to $-6 \mathrm{~cm}$. of water accompanied by a fall in blood pressure. The drug was stopped, the central venous pressure being restored with an intravenous infusion given in $100-\mathrm{ml}$. aliquots of $450 \mathrm{ml}$. of plasma and $450 \mathrm{ml}$. of isotonic saline over three-quarters of an hour. In contrast to the foregoing cases, a considerable decrease in rales occurred during phenoxybenzamine administration, and this continued during the infusion of intravenous fluids. A slight increase in pulse volume occurred and secretion of a small amount of urine began, but cardiac output 
remained low and unconsciousness persisted. The remainder of the phenoxybenzamine was given without any significant effect.

Though some circulatory improvement appeared to occur in these two cases it never seemed likely to be adequate to ensure survival, and both patients died suddenly when there was no medically qualified observer at the bedside. Both were in asystole when seen, and attempted resuscitation was unsuccessful.

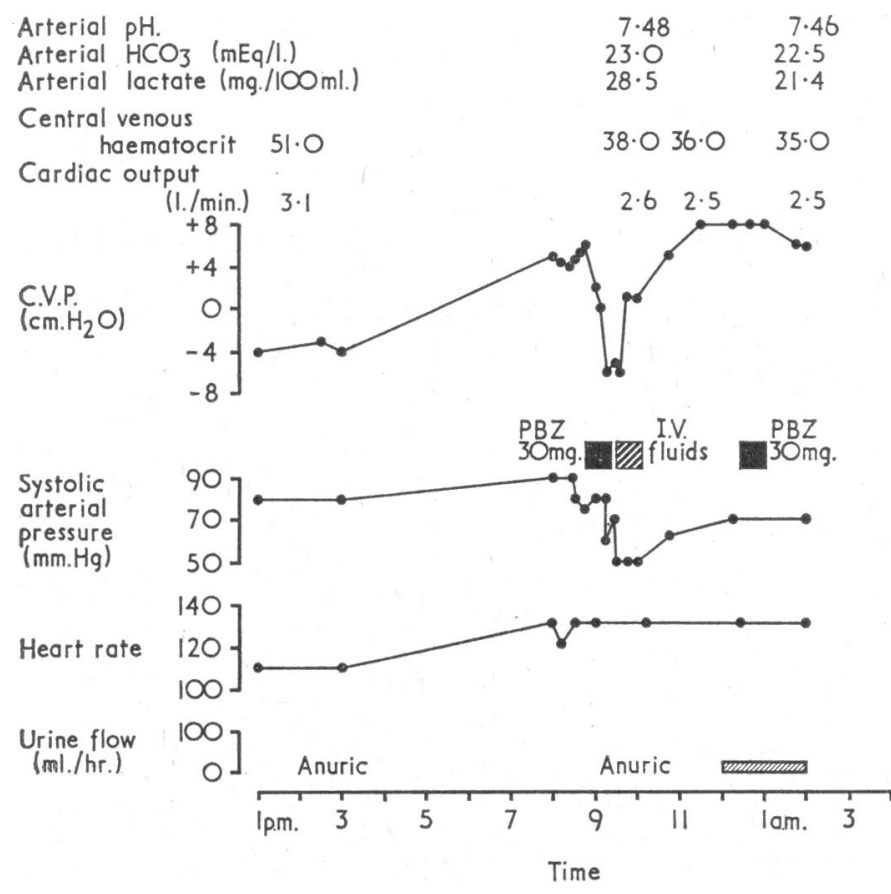

FIG. 2.-Effect of phenoxybenzamine (PBZ) in Case 5. Treatment was temporarily discontinued because of the rapid fall in central venous pressure (C.V.P.) and was restarted after this pressure had been raised with intravenous fluids (see text). Death occurred just after the period shown.

\section{Beneficial Effect (Cases 6 and 7)}

In these cases phenoxybenzamine was again infused slowly and appeared to produce marked circulatory improvement. Initially they were as severely ill as any of the preceding cases. Case 6 had a previous history of two myocardial infarcts, three episodes of left ventricular failure, and one of severe congestive cardiac failure, all requiring admission to hospital. Shock, which was present from the time of onset of his present attack of infarction, was accompanied by sinus bradycardia of $40 / \mathrm{min}$. Atropine $1 \mathrm{mg}$. intravenously increased the rate to $56 / \mathrm{min}$. without any other sign of improvement. Case 7 had a past history of angina and pulmonary embolism and six months previously a myocardial infarct. Three weeks before the present attack haemoptysis due to pulmonary infarction occurred.

Phenoxybenzamine produced similar improvement in both cases (Figs. 3 and 4). A fall in central venous pressure was followed by obvious improvement in pulse volume, skin colour and temperature, mental state, and urine flow, and the arterial pressure gradually rose. Clinically the improvement was maximal after about six hours and was accompanied by increased cardiac output and stroke volume and a fall in arterial blood lactate. Respiratory signs increased in both during phenoxybenzamine administration but were not severe enough for it to be stopped. Case 6, whose chest had been clear, developed wheezing and generalized rhonchi two hours after treatment began. This did not respond to aminophylline $0.5 \mathrm{~g}$. intravenously, but it gradually diminished over the next four hours. Case 7 developed a rise in respiratory rate after one and a half hours, and the rales and rhonchi, which had been present at the lung bases before treatment started, became more widespread, but these signs disappeared as circulatory improvement continued.

Case 6 made a full recovery and was discharged after an uneventful convalescence. Case 7 had two further episodes of shock, which responded to further doses of phenoxybenzamine on each occasion, though similar respiratory signs and an increase in the frequency of ventricular ectopic beats occurred each time during administration of the drug. Six days after the first shock episode, while normotensive, he developed ventricular fibrillation and could not be resuscitated.

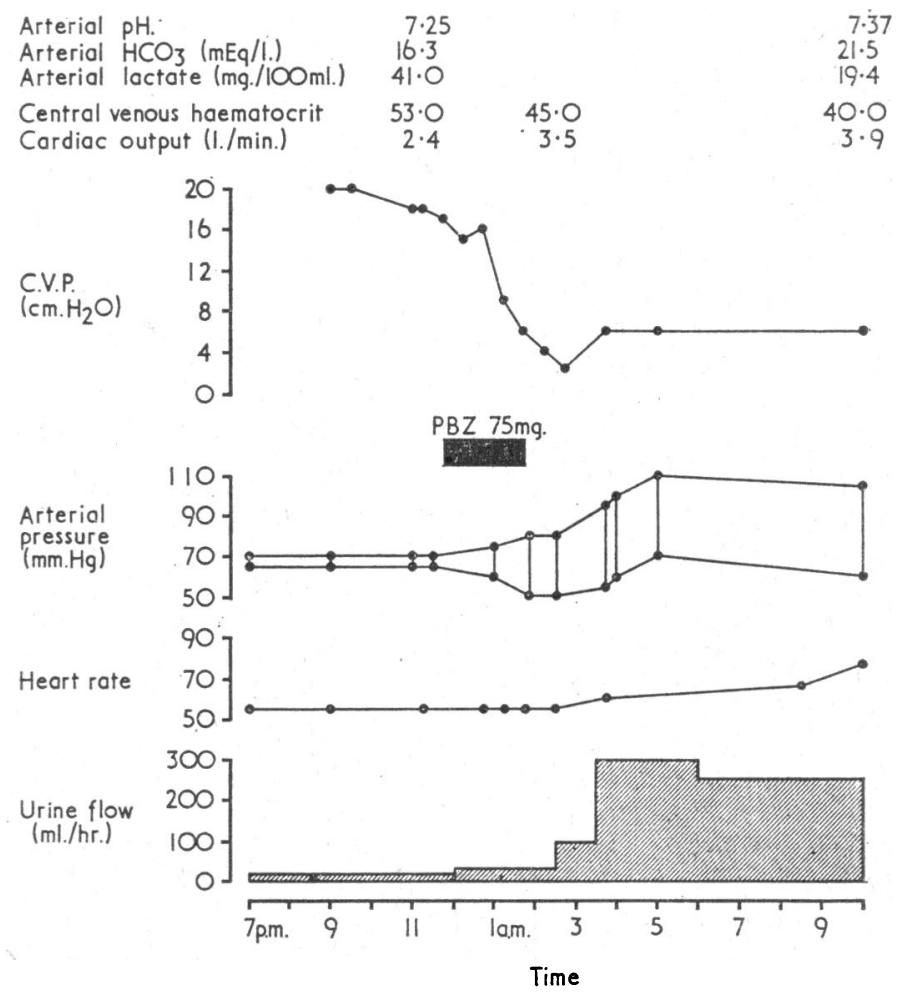

FIG. 3.-Effect of phenoxybenzamine (PBZ) in Case 6.

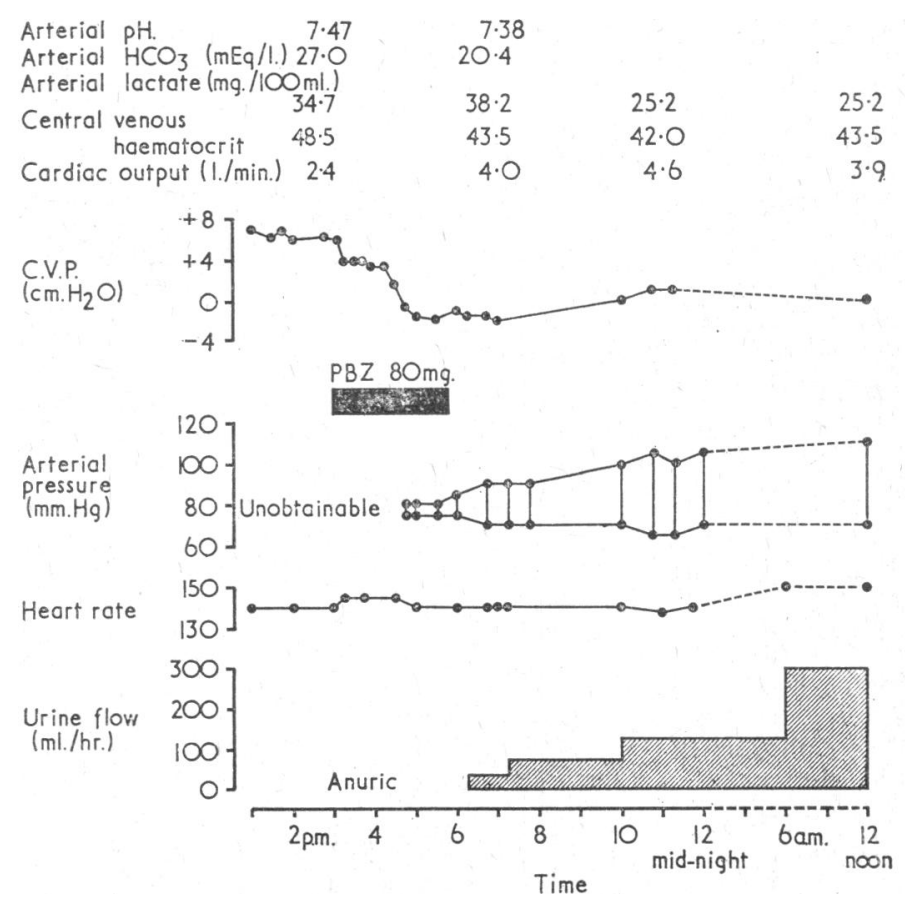

FIG. 4.-Effect of phenoxybenzamine (PBZ) in Case 7 (first episode). 


\section{Discussion}

Although the improvement in the last two cases was very impressive the most striking feature of the series was the appearance of respiratory signs in six of the seven cases. The severity of these seemed to be related to the rate of administration of phenoxybenzamine (Table II), and in the first three patients, who received the drug most rapidly, the wheezing and expiratory difficulty were very pronounced and unlike anything we have seen previously in cases of myocardial infarction. These signs suggest bronchospasm, but we know of no evidence that phenoxybenzamine affects bronchial muscle. They might, however, be due to reflex bronchospasm or to mucosal swelling caused by vasodilatation, possibly accentuated by passive congestion. Dilatation and engorgement of mucosal blood vessels was a very prominent finding at necropsy, together with large amounts of mucus in the bronchi in two of the three severe cases.

TABLE II.-Rate of Administration of Phenoxybenzamine in Patients in Whom Respiratory Signs Increased. In Case 5 a Rate of $1.5 \mathrm{mg} . /$ min. was Associated with a Decrease in Pulmonary Oedema (See Tin.

\begin{tabular}{c|c|l}
\hline $\begin{array}{c}\text { Case } \\
\text { No. }\end{array}$ & $\begin{array}{c}\text { Rate of Administration } \\
\text { (mg./min.) }\end{array}$ & $\begin{array}{c}\text { Respiratory } \\
\text { Signs }\end{array}$ \\
\hline 1 & 2.0 & Severe \\
2 & $2 \cdot 0$ & Severe \\
3 & 0.8 & Severe \\
4 & 0.5 & Mild \\
6 & 0.6 & Moderate \\
7 & 0.4 & Mild \\
\hline
\end{tabular}

The appearance of wheezing or rhonchi was accompanied by the appearance or worsening of signs of pulmonary oedema, and might therefore be a manifestation of it. Obviously, pulmonary oedema might be due to the disease, but its prominence soon after starting treatment with phenoxybenzamine in six of the seven cases suggests a cause-and-effect relationship. This association was totally unexpected, since phenoxybenzamine has been effective in diminishing pulmonary oedema in other circumstances (Nickerson and Gourzis, 1962), as indeed it appeared to be in our Case 5. The mechanism by which such an effect could be produced is far from clear, but certain possibilities may be considered.

Phenoxybenzamine will produce a fall in peripheral resistance, and unless this is accompanied by an equivalent increase in cardiac output the mean arterial pressure will fall, leading to further impairment of coronary artery perfusion; left atrial pressure may then rise sufficiently to cause pulmonary oedema. As it has been shown that sphygmomanometer readings do not reflect intra-arterial pressure accurately in the presence of vasoconstriction (Cohn, 1967), no definite conclusions can be drawn from our observations on blood-pressure changes. Alternatively, a depressant effect on the myocardium might also produce left ventricular failure; but phenoxybenzamine does not block the inotropic effect of adrenaline (Nickerson and Chan, 1961), and we know of no evidence for a direct depressant action.

Alpha-adrenergic blockade, in addition to reducing peripheral resistance, may also affect the pulmonary vascular resistance. Halmágyi et al. (1953) found that alpha-blockade with dibenamine lowered the pulmonary vascular resistance in patients with chronic left heart failure due to various causes, in whom it was raised ; the effect on pulmonary resistance preceded that on peripheral resistance. No such effect was produced when the pulmonary vascular resistance was normal in these conditions. Very little is known about the pulmonary vascular resistance in shock due to myocardial infarction, but it may be inferred from recent reports that the pulmonary resistance may be normal (Kirby et al., 1968) or high (Nixon et al., 1968). The apparently anomalous effect of phenoxybenzamine on pulmonary oedema in shock due to myocardial infarction might therefore be due to differences in pulmonary vascular resistance.
In patients with a normal pulmonary resistance, remaining unaffected by phenoxybenzamine, systemic vasodilatation would result in a shift of blood from the pulmonary to the peripheral vascular bed, and thus reduce the tendency to pulmonary œedema. Conversely, in patients with a raised pulmonary vascular resistance a rapid fall occurring in advance of systemic vasodilatation might produce a rise in left atrial pressure sufficient to precipitate pulmonary oedema before such a shift of blood could occur. In patients with a high pulmonary resistance given phenoxybenzamine slowly the changes might not be so dramatic, and severe pulmonary oedema might be averted by improvement in left ventricular output consequent on the lowered peripheral resistance.

Despite the apparent adverse effects and the fact that only one of the seven patients survived, we believe that this method of treatment is worthy of further investigation. "Shock" is only one mode of death in myocardial infarction, and any treatment directed specifically at this should be assessed, in the first instance, by its effect on shock rather than survival. In this respect our results appear more encouraging, for phenoxybenzamine was effective in a second patient (Case 7, Fig. 4) on three occasions, death due to ventricular fibrillation occurring on the sixth day after admission. Furthermore, it seems possible that the adverse effects produced in at least three patients were due to giving phenoxybenzamine too rapidly, though the rate was always within the generally recommended range.

For full evaluation of the benefits and risks of phenoxybenzamine therapy more detailed haemodynamic studies are required. Measurements of peripheral vascular resistance, which is known to vary considerably from case to case in cardiogenic shock, together with pulmonary resistance and left heart pressures, may establish criteria for selecting patients likely to benefit and for avoiding serious adverse effects. Until such studies are forthcoming, phenoxybenzamine should be used with caution in myocardial infarction, and the rate of administration probably should not exceed $0.5 \mathrm{mg}$. per minute.

We wish to thank the physicians of the Royal Hospital for allowing us to study patients under their care; the research subcommittee of the Birmingham Regional Hospital board for a grant to create the appointment for one of us (J.F.R.) ; Dr. W. A. Hudson for the use of equipment for measuring cardiac output and for helpful comments; Mrs. Pauline Furness for technical assistance; Dr. V. W. Johnson for helpful comments on the manuscript; and Imperial Chemical Industries and Smith Kline and French for generous supplies of Coomassie blue and phenoxybenzamine respectively.

\section{REFERENCES}

Astrup, P., Jørgensen, K., Siggaard Andersen, O., and Engel, K. (1960). Lancet, 1,1035

Cohn, J. N. (1967). 7. Amer. med. Ass., 199, 972.

Cronin, R. F. P., Moore, S., and Marpole, D. G. (1965). Canad. med. Ass. $7 ., 93,57$.

Dietzman, R. H., Lyons, G. W., Bloch, J. H., and Lillehei, R. C. (1967). 7. Amer. med. Ass., 199, 825 .

Dow, P. (1955). F. appl. Physiol., 7, 399.

Epstein, F. H., and Relman, A. S. (1949). New Engl. F. Med., 241, 889. Gabe, I., and Shillingford, J. (1961). Brit. Heart 7., 23, 271.

Halmágyi D., Felkai, B., Iványi, J., Zsótér, T., Tényi, M., and Szücs, Zs. (1953). Brit. Heart f., 15,15 .

Kirby, B. J., MaNicol, M. W., and Tattersfield, A. E. (1968). Lancet, 1, 944.

Kuhn, L. A. (1967). Amer. F. Cardiol., 20, 757.

Lancet, 1966, 1, 645 .

Nickerson, M. (1962). In Shock: Pathogenesis and Therapy, edited by K. D. Bock, p. 356 . Berlin

Nickerson, M., and Chan, G. C-M. (1961). 7. Pharmacol. exp. Ther., 133, 186.

Nickerson, M., and Gourzis, J. T. (1962). F. Trauma, 2, 399.

Nixon, P. G. F., Taylor, D. J. E., and Morton, S. D. (1968). Lancet, 1, 1230.

Oriol, A., and McGregor, M. (1967). Amer. F. Cardiol., 20, 826. J. L. G. (i962). Brit. Heart f., 24, 745

Pentecost, B. L., and Mayne, N. M. C. (1968). Brit. med. F., 1, 830.

Wilson, R. F., Jablonski, D. V., and Thal, A. P. (1964). Surgery, 56, 172 . 